\title{
HUBUNGAN JARAK TEMPAT PELAYANAN DENGAN KETERATURAN KUNJUNGAN POSBINDU PTM PADA LANSIA DI WILAYAH KERJA PUSKESMAS BASUKI RAHMAD KOTA BENGKULU
}

\author{
The Relationship between The Distance of Service Place with The Regulation of \\ Posbindu PTM Visit of Lansia in Working Area of Basuki Rahmad \\ Community Health Center Bengkulu City
}

\author{
Gatot Supriyanto $^{1}$, Eko Puji Astuti ${ }^{1}$, S. Effendi ${ }^{2}$ \\ ${ }^{1}$ Program Studi DIV Kebidanan STIKES Tri Mandiri Sakti Bengkulu \\ ${ }^{2}$ Program Studi Kesehatan Masyarakat STIKES Tri Mandiri Sakti Bengkulu \\ Email: gatotsuprivanto.bkl@gmail.com
}

\begin{abstract}
ARTICLE HISTORY
Received [07 Juli 2020]

Revised [06 Agustus 2020]

Accepted [24 Agustus 2020]

\section{KATA KUNCI:}

jarak tempat pelayanan, kunjungan Posbindu PTM, lansia
\end{abstract}

\section{KEYWORDS:}

distance of service place, elderly, Posbindu PTM visit
ABSTRAK

Jumlah lansia yang berkunjung ke Posbindu di wilayah kerja Puskesmas Basuki Rahmad masih rendah. Penelitian ini bertujuan untuk mempelajari hubungan antara jarak tempat pelayanan dengan kunjungan Posbindu PTM di Wilayah Kerja Puskesmas Basuki Rahmad Kota Bengkulu. Penelitian ini menggunakan pendekatan deskriptif korelational dengan rancangan cross sectional. seluruh lansia yang melakukan kunjungan Posbindu Lansia di wilayah kerja puskesmas Basuki Rahmad Tahun 2018 sebanyak 91 orang lansia dari 4 Posbindu PTM yang aktif diperoleh 91 sampel secara purposive sampling. Pengumpulan data yaitu menggunakan data skunder dan primer. Analisis data dilakukan dengan uji Chi-Square $\left(\chi^{2}\right)$, Uji Contingency Coefficient $(C)$ dan Odd Ratio (OR). Hasil penelitian didapatkan dari 91 sampel terdapat 23 orang kunjungan Posbindu PTM tidak teratur dan 68 orang kunjungan Posbindu PTM teratur, dari 91 sampel terdapat 25 orang jarak tempat pelayanan jauh dan 66 orang jarak tempat pelayanan dekat dan terdapat hubungan yang signifikan antara jarak tempat pelayanan dengan kunjungan Posbindu PTM di Wilayah Kerja Puskesmas Basuki Rahmad Kota Bengkulu, dengan kategori hubungan sedang. Diharapkan kepada pihak Puskesmas untuk dapat melakukan peningkatan pelayanan posbindu yang lebih menarik, melakukan penjemputan lansia dengan jarak rumah yang jauh dan meningkatkan pengetahuan lansia dan keluarga tentang pentingnya kunjungan Posbindu PTM melalui penyuluhan kesehatan sehingga dapat meningkatkan kesadaran lansia dan keluarga untuk malakukan kunjungan Posbndu PTM secara tearatur.

\section{ABSTRACT}

The number of elderly who visited Posbindu PTM in the working area of Basuki Rahmad Community Health Center was still low. The aim of this study was to study the relationship between the distance of service place with the regulation of Posbindu PTM visit of elderly in working Area of Basuki Rahmad Community Health Center, Bengkulu City. This study used a Descriptive Correlational approach with a Cross Sectional design. All elderly people who visited Posbindu PTM in the working area of Basuki Rahmad Community Health Center in 2018 were 91 elderly people from 4 Posbindu PTM who were active and obtained 91 samples by Purposive Sampling. Data used secondary and primary data. Data analysis was performed with the ChiSquare ( $(2)$ test, Contingency Coefficient Test (C) and Odd Ratio (OR). The results obtained: Of the 91 elderly people, there were 23 elderly people who visited Posbindu PTM irregularly and 68 elderly people visited Posbindu PTM regularly, From 91 elderly people, there were 25 elderly people at a distance of service points and 66 elderly people at a distance of service places and there was a significant relationship between the distance of service places with Posbindu PTM visits in Basuki Rahmad Community Health Center in Bengkulu City, with a moderate relationship category. It was expected that Puskesmas can improve Posbindu services to become more attractive, pick up 
lelderly people with a long distance of home and increase the knowledge of elderly and family about the importance of Posbindu PTM visit through health education so as to increase awareness of the elderly and families to conduct Posbndu PTM visits on a regular basis.

\section{Pendahuluan}

Menurut Word Health Organization (WHO) terjadi peningkatan jumlah lansia yang diiringi dengan peningkatan Usia Harapan Hidup (UHH) di dunia. Berdasarkan laporan Perserikatan Bangsa-Bangsa, pada tahun 2000 hingga 2005, persentase populasi lansia di dunia adalah 7,74\% dengan UHHnya sebesar 66,4 tahun. Angka ini diprediksikan akan meningkat pada tahun 2045-2050 menjadi 28,68\% dan UHH-nya menjadi 77,6 tahun. Peningkatan tersebut, akan diiringi dengan peningkatan masalah kesehatan lansia. Tahun 2014, 23\% dari seluruh angka kesakitan dan kematian di dunia terjadi pada lansia (Suparto, 2014).

Umur harapan hidup Indonesia meningkat dari 68,6 tahun pada tahun 2004 menjadi 70,6 tahun pada tahun 2010. Pada tahun 2014 meningkatk menjadi 72 tahun. Kondisi tersebut mengakibatkan terjadinya peningkatan jumlah penduduk lanjut usia. Menurut hasil sensus penduduk tahun 2010 jumlah penduduk lanjut usia Indonesia adalah 18,04 juta jiwa atau $7,6 \%$ dari total jumlah penduduk. Pada tahun 2025 meningkat menjadi 36 juta jiwa (Kemenkes RI, 2017).

Secara nasional terdapat $48,87 \%$ Puskesmas yang melaksanakan pengendalian penyakit tidak menular (PTM) secara terpadu (Puskesmas Pandu PTM). Kepulauan Bangka Belitung merupakan provinsi dengan Puskesmas Pandu PTM terbanyak yaitu 98,39\%. Sebagian besar Puskesmas di DI Yogyakarta dan Jawa Timur juga telah melaksanakan pengendalian PTM secara terpadu, yaitu sebesar 90,08\% dan $87,71 \%$. Namun, proporsi Puskesmas Pandu PTM di Papua masih rendah, yaitu hanya $1,83 \%$ dari Puskesmas yang ada (Kemenkes RI, 2017).

Kegiatan Posbindu PTM yang dilaksanakan oleh desa/kelurahan sebesar 14,85\%. Persentase ini masih di bawah target Rencana Strategis Kementerian Kesehatan tahun 2016 yaitu sebesar 20\%. Jika dilihat menurut provinsi, DKI Jakarta merupakan provinsi dengan desa/kelurahan terbanyak yang melaksanakan Posbindu PTM, yaitu sebesar 87,27\%, urutan kedua Kep. Bangka Belitung dan DI Yogyakarta sebesar 74,42\% dan 53,65\%. Sementara itu, hanya $0,9 \%$ desa di Papua yang melaksanakan Posbindu PTM (Kemenkes RI, 2017).

Menurut Permenkes RI, lansia adalah seseorang yang telah mencapai 60 (enam puluh) tahun ke atas. Lanjut usia berkualitas adalah lanjut usia yang sehat, mandiri, aktif dan produktif (Kemnkes RI, 2016). Lansia adalah seseorang yang telah mencapai usia 60 tahun ke atas. Menua bukanlah suatu penyakit, tetapi merupakan proses yang berangsur-angsur mengakibatkan perubahan kumulatif, merupakan proses menurunnya daya tahan tubuh dalam menghadapi rangsangan dari dalam dan luar tubuh (Kholifah, 2016).

Salah satu pelayanan terhadap lansia di tingkat masyarakat, yang dijalankan oleh Kementrian Kesehatan Republik Indonesia adalah Pos Pembinaan Terpadu (Posbindu) penyakit tidak menular (PTM). Posbindu adalah suatu wadah pelayanan kepada lansia di masyarakat, yang proses pembentukan dan pelaksanaannya dilakukan oleh masyarakat bersama lembaga swadaya masyarakat (LSM), lintas sektor pemerintah dan nonpemerintah, swasta, organisasi sosial dan lain-lain, tujuan meningkatkan peran serta masyarakat dalam pencegahan dan penemuan dini faktor risiko PTM (Kemenkes RI, 2015).

Menurut pendapat Lawrence Green dalam Notoatmodjo (2014), bahwa faktor lingkungan fisik atau letak geografis berpengaruh terhadap perilaku seseorang atau masyarakat terhadap kesehatan. Lansia tidak datang keposyandu di sebabkan karena rumahnya jauh dan pelayanan kesehatan kurang terjangkau.

Jarak tempuh antara rumah lansia dengan pusat pelayanan kesehatan secara 
tidak langsung akan berpengaruh pada lansia dalam melakukan kunjungan. Semakin jauh jarak yang harus ditempuh untuk melakukan kunjungan kesehatan maka akan semakin kecil pula kesempatan yang dimiliki lansia dalam melakukan kunjungan kesehatan (Padilah, 2015).

Hasil penelitian Arfan (2017), tentang faktor frekuensi kunjungan lansia ke posyandu lansia di Kecamatan Pontianak Timur, menunjukkan bahwa jarak merupakan kemampuan manusia dalam mengorganisasikan pengamatan. Jarak merupakan salah satu faktor yang mempengaruhi lansia untuk berkunjung atau tidak berkunjung keposyandu. Para lansia mempunyai persepsi dalam menganalisa tentang jauh tidaknya jarak pelayanan kesehatan, karena jarak merupakan salah satu faktor pendukung seseorang lansia berperilaku.

Di Provinsi Bengkulu berdasarkan data profil kesehatan Tahun 2017, jumlah lansia sebanyak 133.074 jiwa yang terdiri dari 68,305 berjenis kelamin laki-laki dan 64.770 berjenis kelamin perempuan. Lansia yang mendapat pelayanan kesehatan sebanyak 31,613 orang (24\%) yang berarti masih $76 \%$ lansia yang tidak mendapatkan pelayanan kesehatan denagan jumlah pelayanan pada lansia laki-laki sebanyak 14,709 orang dan lansia perempuan sebanyak 16,903 orang (Dinkes Provinsi Bengkulu, 2017).

Berdasarkan data perbandingan Puskesmas di Kota Bengkulu Tahun 2017 jumlah kunjungan lansia ke Posbindu tertinggi berada di Puskesmas Kampung Bali Sebanyak 71,43\%, kedua tertinggi Puskesmas Kuala Lempuing sebanyak $68,45 \%$ dan ketiga tertinggi Puskesmas Pasar Ikan sebanyak 63,14\%. Urutan terendah pertama di Puskesmas Ratu Agung sebanyak 24,74\%, kedua Puskesmas Nusa Indah sebanyak 27,25\% dan ketiga Puskesmas Jalan Gedang sebanyak 31,01\%, namun dari ketiga Puskesmas tersebut pelayanan kesehatan lansia tergabung dalam pelayanan posyandu. Puskesmas Basuki Rahmad sebagai urutan delapan terendah namun memiliki Posbindu PTM yang berjalan aktif setiap bulannya (Dinkes Kota Bengkulu, 2017).

Secara Geografis Puskesmas Basuki Rahmad terletak di Pinggir Kota Bengkulu, tidak ada angkot yang beroperasi di lokasi tersebut dan jarak batas wilayah kerja dengan Puskesmas $>3 \mathrm{~km}$ sehingga kunjungan lansia pada ke pelayanan kesehatan masih rendah. Berdasarkan data Puskesmas Basuki Rahmad Kota Bengkulu dari 4 Posbindu hanya terdapat 90 lansia yang berkunjung terdiri dari Posbindu Sehat Bersama sebanyak 20 orang, Posbindu Sekar sebanyak 24 orang, Posbindu Suka Rami sebanyak 21 dan Posbindu Fatmawati sebanyak 21 orang (Puskesmas Basuki Rahmad, 2019).

Rumusan masalah penelitian adalah "Apakah ada hubungan jarak tempat pelayanan dengan keteraturan kunjungan Posbindu PTM pada lansia di wilayah kerja Puskesmas Basuki Rahmad Kota Bengkulu?". Tujuan penelitian untuk mempelajari hubungan jarak tempat pelayanan dengan keteraturan kunjungan Posbindu PTM pada lansia di wilayah kerja Puskesmas Basuki Rahmad Kota Bengkulu.

\section{Metode Penelitian}

Penelitian ini menggunakan rancangan Deskrptif Korelational dengan pendekatan Cross Sectional karena pengumpulan data variabel independent dan variabel dependent dilakukan pada satu waktu. Populasi dalam penelitian ini adalah seluruh lansia yang melakukan kunjungan Posbindu Lansia di wilayah kerja puskesmas Basuki Rahmad Tahun 2018 sebanyak 91 orang lansia dari 4 Posbindu PTM yang aktif. Pengambilan sampel dalam penelitian Ini Menggunakan Teknik Total sampling. Pengumpulan data dalam penelitian ini menggunakan data skunder dan primer. Untuk mengetahui hubungan antara variabel dilakukan uji chi-square. Untuk mengetahui keeratan hubungannya digunakan uji Contingency $(C)$. 
Hasil Penelitian

1. Analisis Univariat

Analisis ini dilakukan untuk mendapatkan distribusi frekuensi jarak tempat pelayanan sebagai variabel independent dan kunjungan Posbindu PTM sebagai variabel dependent diperoleh data sebagai berikut:

\section{Tabel 1}

Distribusi Frekuensi Kunjungan Posbindu PTM pada Lansia di Wilayah Kerja Puskesmas Basuki Rahmad Kota Bengkulu

\begin{tabular}{ccc}
\hline Kunjungan Posbindu PTM & Frekuensi & Persentase (\%) \\
\hline Tidak Teratur & 23 & 25,3 \\
Teratur & 68 & 74,7 \\
\hline Total & 91 & 100,0
\end{tabular}

Berdasarkan Tabel 1 dari 91 orang lansia yang berkunjung ke Posbindu PTM lansia, terdapat 23 orang lansia yang berkunjung ke Posbindu PTM tidak teratur dan 68 orang

Tabel 2

Distribusi Frekuensi Jarak Tempat Pelayanan Lansia di Wilayah Kerja Puskesmas Basuki Rahmad Kota Bengkulu

\begin{tabular}{ccc}
\hline $\begin{array}{c}\text { Jarak Tempat } \\
\text { Pelayanan }\end{array}$ & Frekuensi & Persentase $(\%)$ \\
\hline Jauh & 25 & 27,5 \\
Dekat & 66 & 72,5 \\
\hline Total & 91 & 100,0 \\
\hline
\end{tabular}

Berdasarkan Tabel 2 dari 91 orang lansia, terdapat 25 orang lansia yang memiliki jarak tempat pelayanan jauh dan 66 orang lansia yang memiliki jarak tempat pelayanan dekat.

\section{Analisis Bivariat}

Analisis bivariat dilakukan untuk mengetahui hubungan antara jarak tempat pelayanan dengan kunjungan Posbindu PTM. Hasil analisis bivariat dapat dilihat pada tabel di bawah ini:

Tabel 3

Hubungan Jarak Tempat Pelayanan dengan Kunjungan Posbindu PTM pada Lansia di Wilayah Kerja Puskesmas Basuki Rahmad Kota Bengkulu

\begin{tabular}{|c|c|c|c|c|c|c|c|c|c|}
\hline \multirow{3}{*}{$\begin{array}{c}\text { Jarak Tempat } \\
\text { Pelayanan }\end{array}$} & \multicolumn{4}{|c|}{ Kunjungan Posbindu PTM } & & & \multirow{3}{*}{$\chi^{2}$} & \multirow{3}{*}{$\mathrm{p}$} & \multirow{3}{*}{$\mathrm{C}$} \\
\hline & \multicolumn{2}{|c|}{ Tidak Teratur } & \multicolumn{2}{|c|}{ Teratur } & \multicolumn{2}{|c|}{ Total } & & & \\
\hline & $\mathrm{F}$ & $\%$ & $\mathrm{~F}$ & $\%$ & $\mathrm{~F}$ & $\%$ & & & \\
\hline Jauh & 16 & 64,0 & 9 & 36,0 & 25 & 100,0 & & & \\
\hline Dekat & 7 & 10,6 & 59 & 89,4 & 66 & 100,0 & 24,616 & 0,000 & 0,481 \\
\hline Total & 23 & 25,3 & 58 & 74,7 & 91 & 100,0 & & & \\
\hline
\end{tabular}

Berdasarkan Tabel 3 dari 25 orang lansia yang memiliki jarak tempat pelayanan jauh, terdapat 16 orang lansia yang berkunjung ke Posbindu PTM secara tidak teratur dan 9 orang lansia yang berkunjung ke Posbindu PTM secara teratur. Dari 65 orang lansia yang memiliki jarak tempat pelayanan dekat, terdapat 7 orang lansia yang berkunjung ke Posbindu PTM secara 
tidak teratur dan 59 orang lansia berkunjung ke Posbindu PTM secara teratur.

Berdasarkan hasil uji statistik Chisquare (Continuity Correction) didapatkan nilai $\chi^{2}=24.616$ dengan $\mathrm{p}=0,000<\alpha=0,05$ berarti signifikan, maka Ho ditolak $\mathrm{Ha}$ diterima. Jadi terdapat hubungan yang signifikan antara jarak tempat pelayanan dengan kunjungan Posbindu PTM pada lansia di wilayah kerja Puskesmas Basuki Rahmad Kota Bengkulu.

Hasil uji Contingency Coefficient didapat nilai $\mathrm{C}=0,481$ dengan $\mathrm{p}=0,000<\alpha$ $=0,05$ berarti signifikan. Nilai $\mathrm{C}$ tersebut dibandingkan dengan nilai $\mathrm{C}_{\max }=0,707$ (karena nilai terendah dari baris atau kolom adalah 2). Karena nilai $\mathrm{C}$ berada di interval $(0,40-0,50)$ artinya tidak jauh dengan nilai nilai $\mathrm{C}_{\max }=0,707$ maka kategori hubungan sedang.

\section{Pembahasan}

Berdasarkan hasil penelitian dari 25 orang lansia yang memiliki jarak tempat pelayanan jauh, terdapat 16 orang lansia berkunjung ke Posbindu PTM tidak teratur karena jarak tempat pelayanan yang jauh berdampak pada kurang baiknya sikap dan minat lansia untuk berkunjung ke Posbindu sehingga lansia tidak dapat berkunjun ke Posbindu PTM secara teratur.

Berdasarkan hasil penelitian dari 25 orang lansia yang memiliki jarak tempat pelayanan jauh, terdapat 9 orang lansia teratur seluruhnya dengan jenis kelamin perempuan karena 2 orang lansia yaitu Ny.A dan Ny.W usia 64 tahun memiliki kendaraan pribadi, 1 orang lansia berusia 80 tahun diantar untuk kontrol penyakit dan 6 orang lansia berusia $68,70,81,81,82,83$ tahun diantar oleh keluarga untuk melakukan pemeriksaan kesehatan dan dapat mengikuti kegiatan Posbindu PTM.

Berdasarkan hasil penelitian dari 66 orang lansia yang memiliki jarak tempat pelayanan dekat, terdapat 7 orang lansia tidak teratur berkunjung ke Posbindu PTM yaitu karena 2 orang lansia berusia 61 dan 62 tahun mengalami penyakit DM yang sedang kambuh, 1 orang lansia berusia 64 tahun sibuk berdagang, 2 orang lansia berusia 60 dan 68 tahun mengalami penyakit asam urat yang sering kambuh, 1 orang lansia berusia 69 tahun lebih suka kontrol kesehatan ke kelinik dan 1 orang lansia berusia 78 tahun mengalami penyakit stroke ringan sehingga lansia tidak dapat berkunjung secara teratur.

Dari 66 orang lansia yang memiliki jarak tempat pelayanan dekat, terdapat 59 orang lansia secara teratur melakukan kunjungan Posbindu PTM karena jarak tempat pelayanan dekat membuat lansia lebih mudah untuk menjangkau layanan kesehatan yang diberikan sehingga lansia dapat melakukan kunjungan Posbindu PTM secara teratur.

Berdasarkan hasil uji Chi-Square (Continuity Correction) diperoleh hubungan yang signifikan antara jarak tempat pelayanan dengan Kunjungan Posbindu PTM. Hasil penelitian ini juga sejalan dengan pendapat Menurut pendapat Lawrence Green dalam Notoatmodjo (2014), bahwa faktor lingkungan fisik /letak geografis berpengaruh terhadap perilaku seseorang /masyarakat terhadap kesehatan. Lansia tidak datang ke Posyandu disebabkan karena rumahnya jauh dan pelayanan kesehatan kurang terjangkau.

Hasil penelitian ini juga sejalan dengan yang dilakukan Arfan (2017), menunjukkan bahwa jarak merupakan kemampuan manusia dalam mengorganisasikan pengamatan. Jarak merupakan salah satu faktor yang mempengaruhi lansia untuk berkunjung atau tidak berkunjung ke Posyandu. Dimana dalam hal ini para lansia mempunyai persepsi dalam menganalisis tentang jauh tidaknya jarak pelayanan kesehatan, karena jarak merupakan salah satu faktor pendukung yang memungkinkan seseorang berperilaku.

Hasil uji Contingency Coefficient didapat kategori hubungan sedang. Kategori hubungan sedang menunjukkan bahwa ada faktor lain yang dapat mempengaruhi kunjungan Posbindu PTM selain dari jarak tempat pelayanan diantaranya penyakit yang diderita, pengetahuan lansia, kendaraan, dukungan keluarga dan kesibukan bekerja. 
Kesimpulan

1. Dari 91 orang lansia, terdapat 68 orang lansia yang melakukan kunjungan Posbindu PTM teratur.

2. Dari 9 1orang lansia, terdapat 25 orang jarak tempat pelayanan jauh dan 66 orang lansia yang memiliki jarak tempat pelayanan dekat.

3. Terdapat hubungan yang signifikan antara jarak tempat pelayanan dengan kunjungan Posbindu PTM di Wilayah Kerja Puskesmas Basuki Rahmad Kota Bengkulu, dengan kategori hubungan sedang.

\section{Daftar Pustaka}

Arfan, I. (2017). Faktor Frekuensi Kunjungan Lansia ke Posyandu Lansia di Kecamatan Pontianak Timur. Jurnal Vokasi Kesehatan, 3 (2) : 92-97. Diunduh dari : http://ejournal.poltekkespontianak.ac.id/index.php/JVK.

Dinkes Provinsi Bengkulu. (2017). Profil Kesehatan Provinsi Bengkulu. Bengkulu: Dinkes Provinsi Bengkulu.
Kemenkes RI. (2017). Profil Kesehatan Indonesia. Jakarta: Kementerian kesehatan RI.

Kemenkes RI. (2015). Buku Penyelenggaraan Posbindu PTM. Jakarta: Kemenkes RI.

Kholifah, S. N. (2016). Keperawatan Gerontik. Jakarta : Kemenkes RI.

Notoatmodjo, S. (2014). Promosi Kesehatan dan Ilmu Perilaku. Jakarta: Rineka Cipta.

Padilah. (2015). Konsep Kebidanan. Yogyakarta : Nuha Medika.

Puskesmas Basuki Rahmad. (2019). Data Kunjungan dan Jumlah Posbindu PTM di Puskesmas Basuki Rahmad. Bengkulu : Puskesmas Basuki Rahmad.

Suparto, T.A, Sunjaya, D.K., \& Susanti, R. D. (2017). Factors That Affect Posbindus' Performance in Dayeuhkolot Kabupaten Bandung. IOP Conf. Series: Materials Science and Engineering, 180 : 012264. Diunduh dari https://www.researchgate.net/publication 1315535023 Factors That Affect Posbi ndus'_Performance_in_Dayeuhkolot_Ka bupaten Bandung. 